\title{
Micromachining of hardened Portland cement pastes using femtosecond laser pulses
}

\section{Journal Article}

\section{Author(s):}

Trtik, P.; Hauri, C.P.

Publication date:

2007

Permanent link:

https://doi.org/10.3929/ethz-b-000003484

Rights / license:

In Copyright - Non-Commercial Use Permitted

Originally published in:

Materials and Structures 40(7), https://doi.org/10.1617/s11527-006-9164-2 


\title{
Micromachining of hardened Portland cement pastes using femtosecond laser pulses
}

\author{
P. Trtik · C. P. Hauri
}

Received: 4 October 2005/ Accepted: 2 February 2006/Published online: 19 July 2006

(C) RILEM 2006

\begin{abstract}
Femtosecond laser pulses (30 fs in length) of various energies were utilised for production of single and multiple overlapping ablation sites on flat polished surfaces of hardened Portland cement pastes. In order to assess the sizes of the ablation sites and possible subsurface laser-induced damage, the ablation sites were investigated using environmental scanning electron microscopy (ESEM) - both from normal top-down view and in cross-sections. Furthermore, approximately $10-\mu \mathrm{m}$ wide notches were produced using femtosecond pulses on cylindrical microspecimens $(150 \mu \mathrm{m}$ in diameter $)$ of hardened Portland cement pastes. In addition to electron microscopy observations, several microspecimens were investigated using synchrotronbased X-ray computed microtomography $(\mathrm{SR} \mu \mathrm{CT})$. The results suggest that production of "damage-free" samples for micromechanical testing of hardened Portland cements pastes is possible.
\end{abstract}

\footnotetext{
P. Trtik $(\bowtie)$

Institute for Building Materials (IfB), ETH Zurich,

Zürich CH-8093, Switzerland

e-mail: pavel.trtik@imes.mavt.ethz.ch

C. P. Hauri

Laboratoire d'Optique Appliquee (LOA), Ecole

Polytechnique, Palaiseau Cedex 91761, France
}

Résumé Des impulsions laser (de durée 30 fs) et d'énergie variable ont été utilisées pour produire une ablation ponctuelle ou linéique à la surface d'un ciment durci de type Portland et préalablement polie. Pour déterminer la taille des impacts et d'éventuels dommages causés par le laser sous la surface, les points d'impact ont été visualisés à l'aide de la technique de l'ESEM (microscope électronique à balayage environnemental). De plus, des piliers de 10 micromètres de diamètre environ ont été réalisés par ablation femtoseconde sur des échantillons cylindriques de 150 microns de diamètre. Pour compléter les observations faites au microscope électronique, certains échantillons ont été observés grâce à la technique $S R \mu C T$ (synchrotron-based X-ray computed microtomography). Les résultats montrent que la production d'échantillons non-endommagés de ciment de type Portland pour des tests micro-mécaniques ultérieurs est possible.

Keywords Femtosecond laser pulses ·

Hardened cement paste $\cdot$ Micromachining

\section{Introduction}

The mechanical testing of samples of sub-mm dimensions (further called 'microspecimens') is necessary for the better understanding of fracture processes that occur in cementitious and other 3D 
disordered materials. Moreover, the mechanical testing of samples of such dimensions is required for validation of micromechanical models of cementitious materials. Crack detection in these materials can be carried out with sub-micron resolution using synchrotron-based X-ray microtomography techniques (SR $\mu \mathrm{CT})$ and environmental scanning electron microscopy (ESEM). The preparation of microspecimens of cementitious materials is not straightforward. Mechanical tools, such as high precision wire saws are too crude on this scale and cannot be used for preparation of microspecimens of hardened Portland cement pastes. The micromachining capability of focused ion beam milling (FIB) [1] would be sufficient. However, the applicability of FIB techniques for such application is questionable due to (a) the necessity to expose the material to a high-vacuum environment and (b) the extensive amount of time needed for removal of material on this - for FIB milling relatively very large scale. For that reason, micromachining capability of femtosecond laser pulses was investigated for the particular case of hardened Portland cement pastes.

\subsection{Femtosecond laser pulses}

Laser pulses are nowadays widely used for (micro-)machining of various materials. In principle, the laser pulses can be divided into two groups based on the heat diffusion time: long pulses and ultrashort pulses. Even though the heat diffusion time is dependent on the thermal conductivity of each particular material, the approximate division between long and ultrashort pulses can be drawn at the level of about 1 picosecond. Consequently, ultrashort pulses are usually operated with pulse length in the range of tens/hundreds of femtoseconds.

Thanks to the pulse length, which is much shorter than the heat diffusion time, the femtosecond laser systems have potential to induce much less microstructural damage/changes to the micromachined material. Such damage/changes include:

- formation of surface recast layer around the laser machined site. Such a recast layer is usually made of material of different/changed properties than that of the unprocessed material further away from the ablation site.

- surface and sub-surface microcracks in vicinity of the ablation sites due to shock wave propagation.

- heat-affected zone in the vicinity of ablation site.

A concise literature review on laser beam machining has been recently published by Meijer [2]. The majority of literature dealing with laser machining is focused on machining relatively homogeneous materials such as quartz [3] or diamond [4]. Investigation on the femtosecond ablation of metals have also been carried out [5], and there are several publications on laser beam machining of ceramics and composite materials $[6,7]$. The general trend is that less microstructural damage is imposed into the materials with the decrease in the length of the laser pulse. However, it should be noted, that in the case of ablation of indium phosphide [8], it was reported that femtosecond pulses induce more sub-surface damage than the nanosecond ones.

\section{Sample preparation}

All the samples were produced from Portland cement CEM I 42.5 N. The chemical composition of the used cement is shown in Table 1.

The water to cement (W/C) ratio was kept uniform for all the samples and was equal to 0.33 . First, $66 \mathrm{ml}$ of water was poured into a vessel containing $200 \mathrm{~g}$ of Portland cement. Then, the mixture was mixed for several minutes using a high-speed mixing device.

Two types of samples were produced for this investigation (i) flat polished surfaces and

Table 1 Chemical composition, density and surface area of the Portland cement used

\begin{tabular}{|c|c|c|}
\hline Chemical analysis [\%] & $\begin{array}{l}\mathrm{CaO} \\
\mathrm{SiO}_{2} \\
\mathrm{Al}_{2} \mathrm{O}_{3} \\
\mathrm{Fe}_{2} \mathrm{O}_{3} \\
\text { other }\end{array}$ & $\begin{array}{r}64.2 \\
19.8 \\
4.7 \\
2.7 \\
8.6\end{array}$ \\
\hline $\begin{array}{l}\text { Density }\left[\mathrm{kg} / \mathrm{m}^{3}\right] \\
\text { Blaine surface area }\left[\mathrm{cm}^{2} / \mathrm{g}\right]\end{array}$ & & \\
\hline
\end{tabular}


(ii) cylindrical microspecimens. While the flat polished specimens were produced for the investigation of the assessment of the possible laser-induced microstructural damage, the purpose of production of the cylindrical microspecimens was to investigate the capability of femtosecond laser pulses in a realistic micromachining application (i.e. in this particular case the production of a circular notch on a cylindrical microspecimen).

\subsection{Flat polished surfaces}

For the flat polished surfaces, the fresh paste was cast into cylindrical formwork of $12 \mathrm{~mm}$ in diameter and $70 \mathrm{~mm}$ in length and vibrated for approximately $1 \mathrm{~min}$. The samples were then placed into a climate box at $25^{\circ} \mathrm{C}$ and $75 \%$ R.H. The cylinders were demoulded after 3 days and further stored under the same conditions. One day before testing at the age of 90 days, approx. $3 \mathrm{~mm}$ thick slices were cut from the cylinders using a high precision wire saw (wire diameter of $150 \mu \mathrm{m})$. Next, the slices were glued on standard aluminium stubs used in electron microscopy, and were ground and polished using various grinding and polishing cloths. After each grinding and polishing step, the treated surface was cleaned in an ultrasonic bath.

\subsection{Cylindrical microspecimens}

Special moulds, made of PTFE sheets of $0.25 \mathrm{~mm}$ thickness, were developed for the production of the microcylinders. First, a round coupon of $12 \mathrm{~mm}$ in diameter was cut out from the PTFE sheets. In the next phase, seven holes of $150 \mu \mathrm{m}$ in diameter were drilled in the vicinity of the centre of the coupon using high-precision drillers. The samples were cast in such a manner that the whole coupon was submerged into the fresh cement paste, while being held in tweezers. Having been removed from the fresh paste, the coupon was then placed in small plastic bag. The bag, containing several coupons, was stored in a climate box at $25^{\circ} \mathrm{C}$ and $75 \%$ R.H. On the day of the laser experiment, the material on the top and bottom of the coupon was carefully removed, leaving seven samples of $150 \mu \mathrm{m}$ in diameter and approximately $250 \mu \mathrm{m}$ in height embedded in the PTFE coupon. The samples were then carefully demoulded under an optical microscope by cutting the PTFE sheet away using a sharp razor blade, after which they were glued axisymmetrically on the top of the special needle-like brass holders.

\section{Femtosecond laser test arrangement}

All the experiments reported in this paper were carried out using the ultrashort laser facility at the Institute for Quantum Electronics, ETH Zurich. The laser system (shown in Fig. 1) is a conventional Ti:sapphire-based Chirped Pulse Amplifier (CPA) system. It delivers pulses centred around the wavelength of $800 \mathrm{~nm}$ and of $30 \mathrm{fs}$ duration at variable repetition rates from $0.5 \mathrm{~Hz}$ to $1 \mathrm{kHz}$. To best match the required energy level for processing of hardened Portland cement paste, the laser pulse was attenuated by a neutral density filter wheel. This way the energy could be continuously varied within $3 \mu \mathrm{J}$ and $12 \mu \mathrm{J}$. After attenuation, the beam was focused by a spherical mirror (radius of curvature $-150 \mathrm{~mm}$ ) to a spot size of $12 \mu \mathrm{m}(\mathrm{FWHM})$ and $20 \mu \mathrm{m}\left(1 / \mathrm{e}^{2}\right)$, respectively (see Fig. 2).

For geometrical reasons, the laser test arrangement differed slightly for the ablation of flat polished surfaces and cylindrical microspecimens. For the latter, the focussing arrangement was changed from the above-mentioned spherical

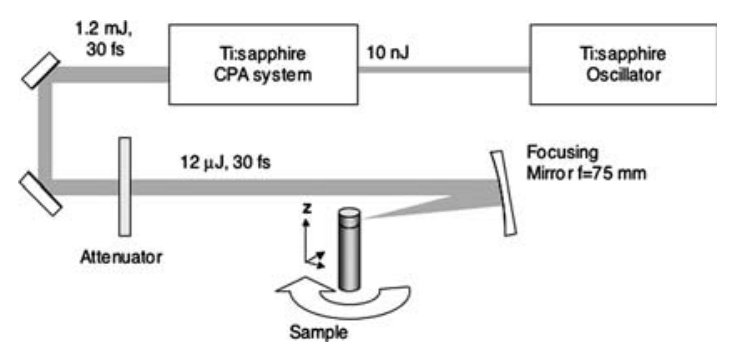

Fig. 1 Test arrangement for ablation of cylindrical microspecimens: Amplifier system consisting of a broadband oscillator and a Chirped Pulse Amplifier (CPA) system yielding $1.2 \mathrm{~mJ}$ pulses with a duration of $30 \mathrm{fs}$. A portion of this beam is used for microprocessing of the cement target. The beam is focused by a spherical mirror to a spotsize of $12 \mu \mathrm{m}$ (FWHM) in diameter 


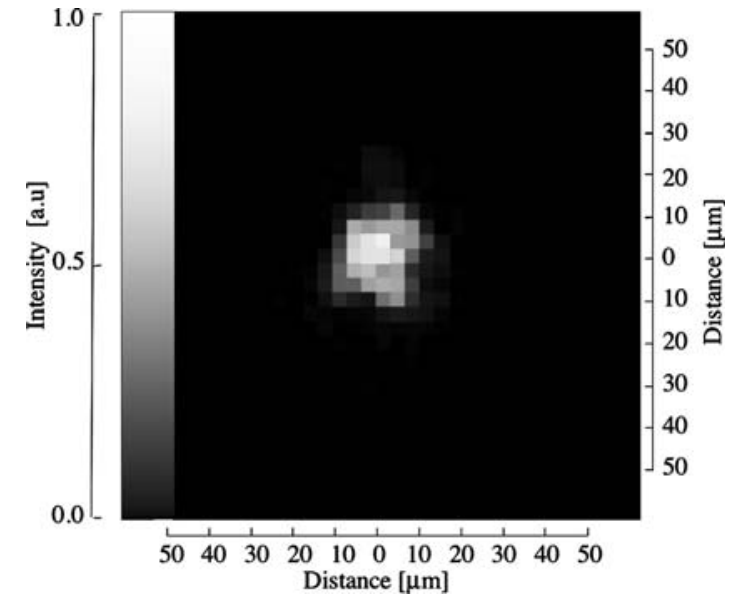

Fig. 2 Beam profile in the focal spot behind the spherical mirror. More than half of the pulse energy is deposited within a spot size of $144 \mu \mathrm{m}^{2}$

mirror to a spherical lens with the identical focal distance. The target to be ablated was mounted on a high-accuracy rotational stage to provide best stability and reproducibility.

Theoretically calculated curve of the beam waist is shown in Fig. 3 . The beam waist remains very uniform over a distance of $\pm 100 \mu \mathrm{m}$ from the focal point. It shows that - within the shown distance interval - the size of the beam waist changes only marginally and hence the position of the target in the direction of the propagation of the laser pulse has only minimal influence on the fluence of the laser pulse. Since the sample positioning in the laser beam was of higher precision than $100 \mu \mathrm{m}$, it is expected that the ablation capability was largely independent of the sample position in the direction of the beam propagation.

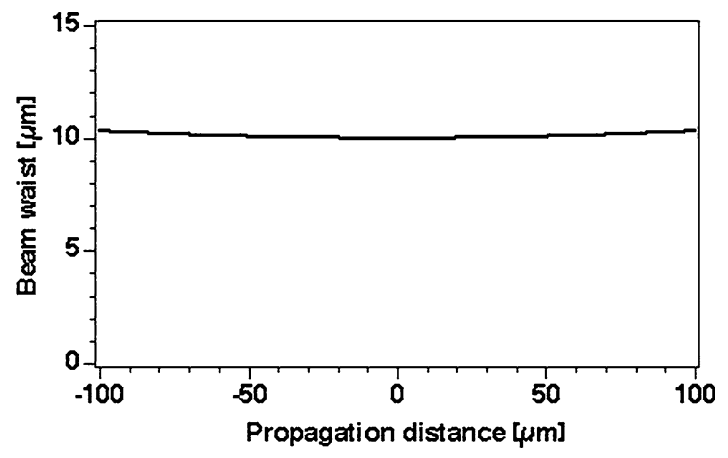

Fig. 3 Theoretically calculated curve of the beam waist

\section{Experimental}

\subsection{Ablation of flat polished surfaces}

In the first stage of the investigation, lines/ grooves, built of overlapping single femtosecond laser shots, were carried out on the flat polished surfaces of hardened Portland cement. The incidence angle between the ablated surface and the laser beam was equal to approx. $90^{\circ}$. The ablation sites were placed at $20 \mu \mathrm{m}$ distance from each other. The energy of the pulses was the experimental parameter and was set to 12,9 and $6 \mu \mathrm{J}$.

In the second stage, lines of overlapping multiple laser shots were carried out. In this case, the energy of the pulses was set to $3 \mu \mathrm{J}$ and the rate of repetition of laser pulses was set at $1,000 \mathrm{~Hz}$. In this mode, the sample was moved under the laser beam in steps of $10 \mu \mathrm{m}$ per second using a precision translation table equipped with micrometers. In all the cases, lines of overlapping ablation sites of approx. $2 \mathrm{~mm}$ length were produced.

\subsection{Ablation of cylindrical microspecimens}

A groove of overlapping ablation sites was produced on the surface of the cylindrical microspecimens. For the ablation process, the cylindrical microspecimens were fitted into an axisymmetrically revolving sample holder. All the experiments using microcylinders were carried out using laser pulses of $12 \mu \mathrm{J}$. The grooves were produced using 1 and 2 pulses per ablation site, respectively, and after the ablation of each site the sample was rotated 7.5 and $15^{\circ}$, respectively. Consequently, there were either 24 or 48 ablation positions around the perimeter of each cylinder and, hence, the production of the entire notch would require between 24 and 96 laser pulses. The incidence angle of the laser beam on the sample was approx. $45^{\circ}$.

\section{Microscopic investigations of the ablation sites}

The ablation sites were investigated using (i) environmental scanning electron microscopy and (ii) synchrotron-based X-ray microtomography. 


\subsection{Environmental scanning electron microscopy (ESEM)}

Environmental scanning electron microscopy revealed that in the vicinity of the ablation sites, no recast layers on the sample surfaces were deposited in any of the cases investigated. The visible surface cracks, that could have been possibly associated with any negative influence of the ablation process on the microstructure of cementitious material, seemed not to appear in any larger density than in areas further away from the ablation sites.

\subsubsection{Flat polished surfaces}

Figures 4 and 5 show typical lines of overlapping single laser shots for 12 and $9 \mu \mathrm{J}$, respectively. The size of the ablation sites differed significantly for each ablation site, but, in general, it was possible to observe, that the ablation sites, that were carried out using $12 \mu \mathrm{J}$ pulse energy, were larger (from 15 to $40 \mu \mathrm{m}$ in size) than those carried out with $9 \mu \mathrm{J}$ (from 10 to $30 \mu \mathrm{m}$ in size). In few cases of pulses of $9 \mu \mathrm{J}$ in energy, no observable ablation sites were produced, thus leaving a gap in the ablated groove. No ESEM-observable ablation sites were found for single laser shots carried out using $6 \mu \mathrm{J}$ pulse energy.

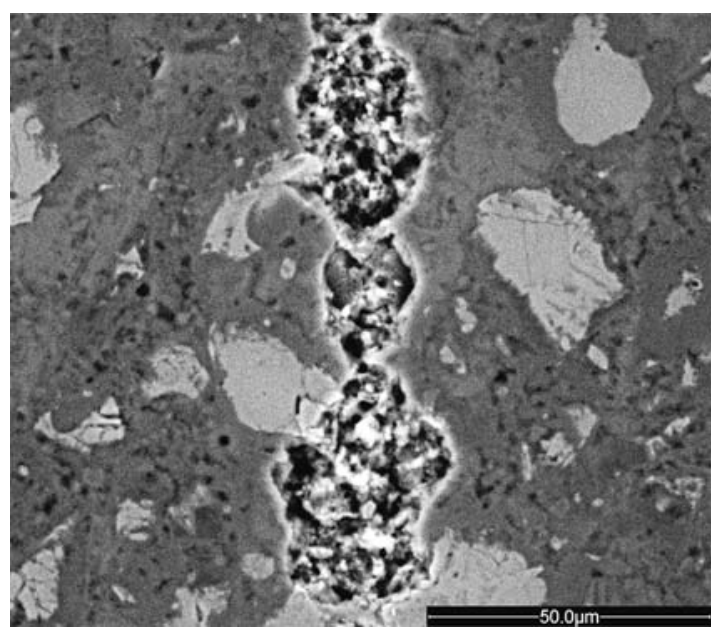

Fig. 4 Example of a back-scattered electron (BSE) image of a line of the overlapping laser ablation sites carried out using $30 \mathrm{fs}$ single pulses of $12 \mu \mathrm{J}$ energy

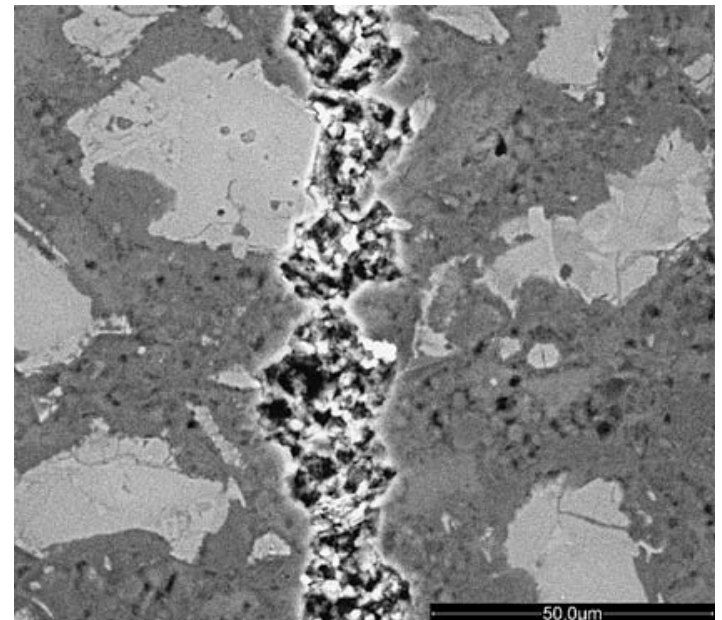

Fig. 5 Example of a BSE image of a line of the overlapping laser ablation sites carried out using $30 \mathrm{fs}$ single pulses of $9 \mu \mathrm{J}$ energy

In Fig. 6, a groove produced by overlapping multiple laser shots of $3 \mu \mathrm{J}$ pulse energy is shown. In comparison to the single shots of higher pulse energies this experimental arrangement produced a much more uniform groove. The width of the groove on the surface was found to be approx. $10 \mu \mathrm{m}$.

In order to assess depth profiles of the laser grooves, some of the ablation sites were also investigated in ESEM using stereological imaging. Figures 7 and 8 show examples of the depth profiles for grooves micromachined with 12 and

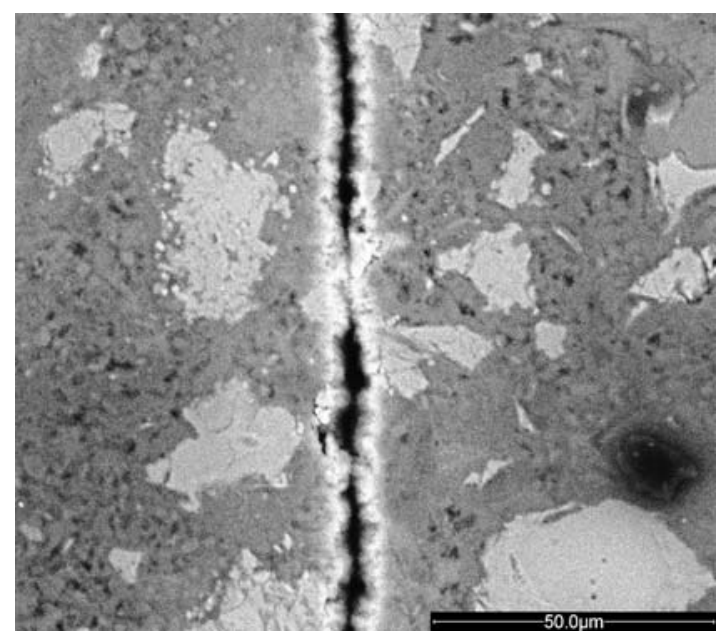

Fig. 6 Example of a BSE image of a line of the overlapping laser ablation sites carried out using $30 \mathrm{fs}$ multiple pulses of $3 \mu \mathrm{J}$ energy 


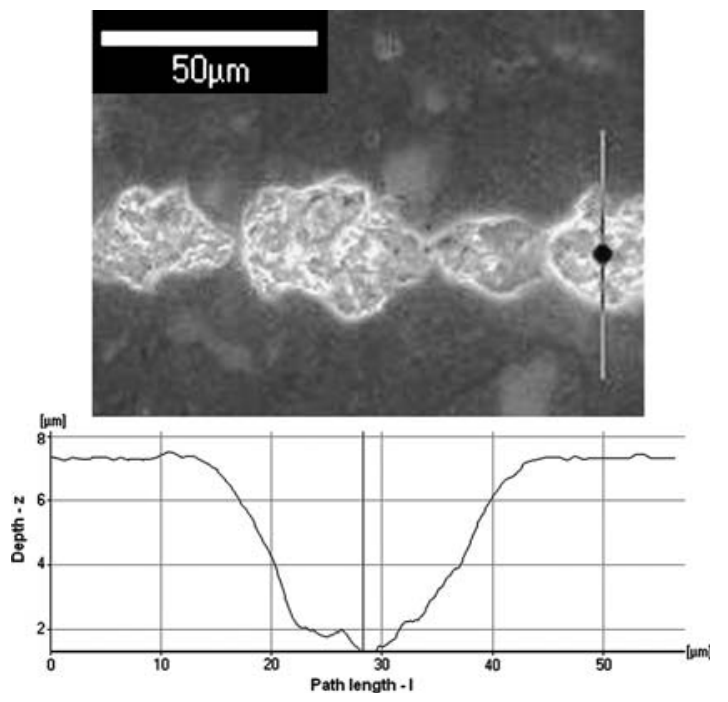

Fig. 7 Depth profile of a single overlapping laser ablation site carried out using $12 \mu \mathrm{J}$ pulse energy. The depth of the ablation site equals approximately $6 \mu \mathrm{m}$

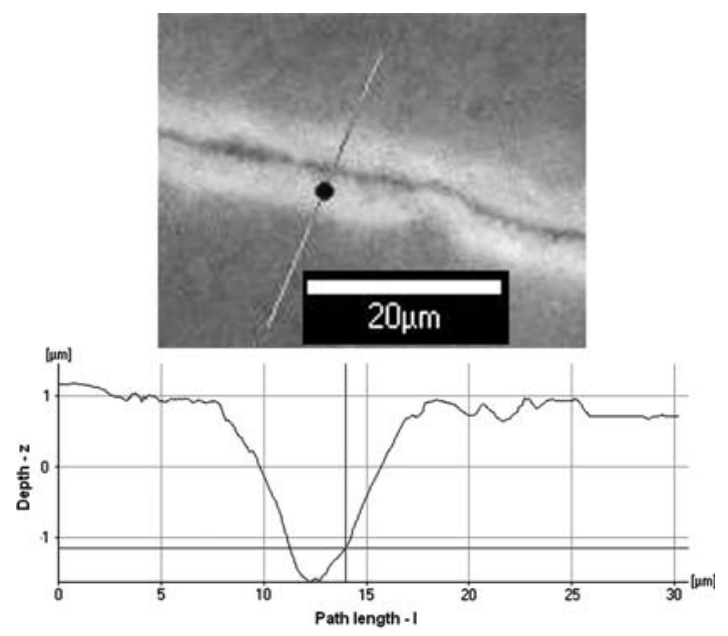

Fig. 8 Depth profile of a single overlapping laser ablation site carried out using $12 \mu \mathrm{J}$ pulse energy. The depth of the ablation site equals approximately $2.5 \mu \mathrm{m}$

$3 \mu \mathrm{J}$ laser pulses, respectively. The depth profiles showed that the ablation sites carried out using single laser shots of 12 and $9 \mu \mathrm{J}$ are of larger 'width-to-depth' ratio than those carried out by multiple laser shots of $3 \mu \mathrm{J}$.

\subsubsection{Cylindrical microspecimens}

The ESEM investigation of the microcylinders revealed that a relatively uniform notch on a microcylinder can be produced using femtosecond laser pulses (see Fig. 9). Figure 10 shows an image of a groove on a microcylinder, which was ablated using 2 shots per ablation position and 48 positions around the perimeter of the cylinder.

The width of the notch at the surface of the cylinder did not differ significantly for various test arrangements and it equalled approx. 10-15 $\mu \mathrm{m}$. The number of pulses had a larger influence on the depth of the notch. The question of the notch depth will be discussed in detail in the following sections.

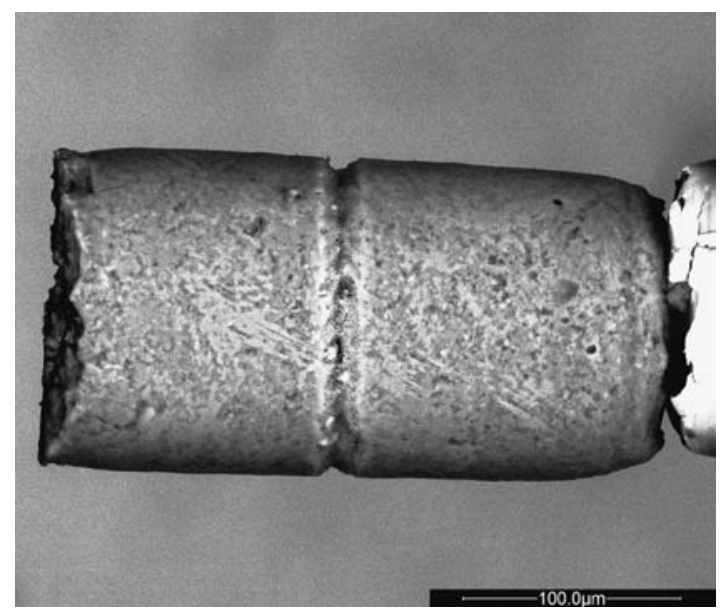

Fig. 9 ESEM image of a microcylinder of hardened Portland cement paste modified by overlapping laser shots using $30 \mathrm{fs}$ pulse length and $12 \mu \mathrm{J}$ energy

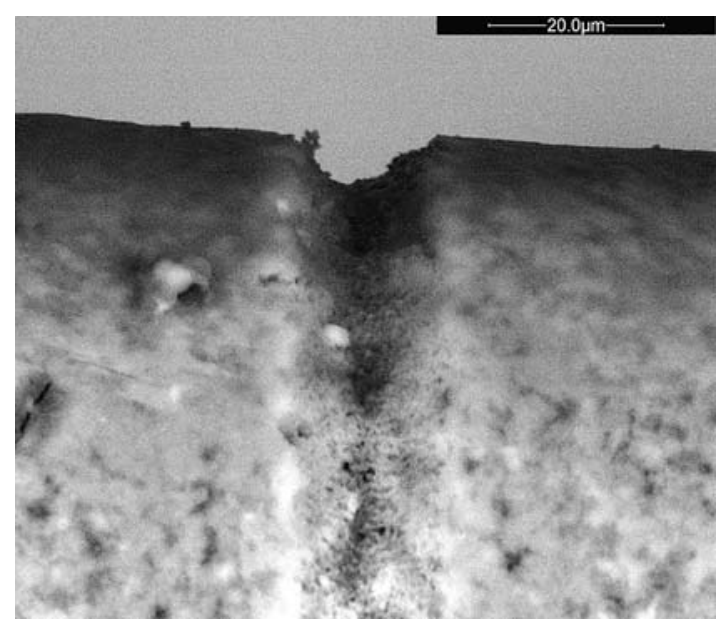

Fig. 10 Detail of the notch shown in Fig. 9 


\subsection{Cross-sections through the ablation sites observed by ESEM}

In order to obtain insight into the possible microstructural defects induced into the material by laser pulses, the samples were impregnated with an epoxy resin and cross-sectioned by grinding and polishing. The sub-surface regions of some of the ablation sites were thus revealed and subsequently observed using ESEM. From such images, the depth profiles of the ablation sites could be estimated. Since it was not possible to assess the microstructure of the material in three-dimensions before the samples were ablated, it cannot be ascertained whether any microstructural damage had been induced into the material microstructure by the laser pulses. However, it is possible to compare the microstructure of the material in very close vicinity of the ablation site with that of the material further away from the site. No damage that could be clearly attributed to the laser ablation process could be deduced from such a comparison.

\subsubsection{Flat polished surfaces}

Since hardened Portland cement paste is a 3D disordered material, there is no 'typical' image of the cross-section of an ablation site in the microstructure of cement paste. Hence, only examples of the images showing the microstructure underneath some ablation sites are presented. Figures 11 and 12 show such examples for ablation sites produced by single overlapping laser pulses of 12 and $9 \mu \mathrm{J}$. It is worth noting that both of the cross-sections of the ablation sites produced with the single pulse were relatively shallow, their maximum depth was equal to approximately 5 and $3 \mu \mathrm{m}$, for $12 \mu \mathrm{J}$ and $9 \mu \mathrm{J}$ pulse energies, respectively. Figure 13 shows an example of the cross-section through the groove ablated using the multiple laser pulses of $3 \mu \mathrm{J}$ pulse energy. In this particular case, the width and depth of the ablation site were approx. 7 and $5 \mu \mathrm{m}$, respectively. It should be also noted that the cross-sections through the ablation sites of the single overlapping laser shots exhibited significant surface roughness, while the ablation sites of the multiple laser shots produced relatively sharp grooves of much lower roughness.

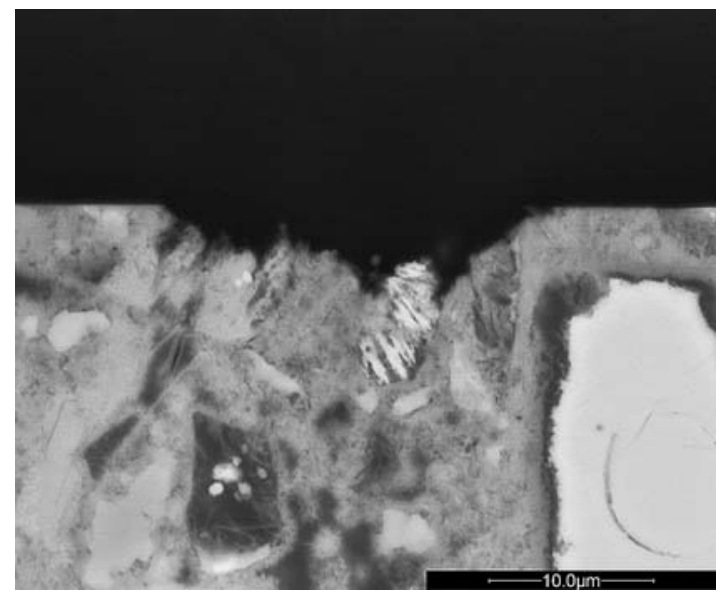

Fig. 11 ESEM image showing a cross-section of an ablation site of a single overlapping laser pulse of $12 \mu \mathrm{J}$ energy

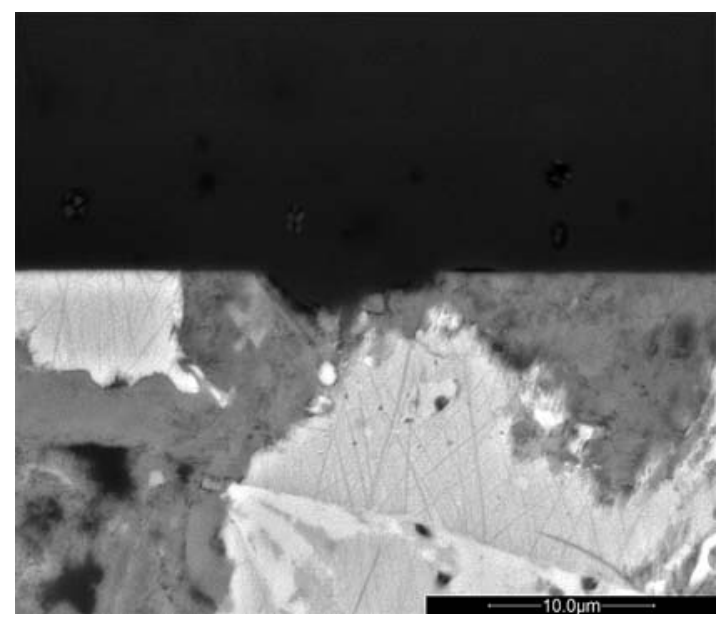

Fig. 12 ESEM image showing a cross-section of an ablation site of a single overlapping laser pulse of $9 \mu \mathrm{J}$ energy

\subsubsection{Cylindrical microspecimens}

Before the cross-sectioning, the ablated microspecimens were impregnated in the same way as the flat polished surfaces. Figure 14 shows an example of the cross-section through the microspecimen that was ablated using 2 pulses per ablation site and 48 laser pulses alongside the circumference, while Fig. 15 shows detail one of the ablation sites.

Visual observation of subsurface region in vicinity of the ablation sites revealed again that hardly any apparent microstructural change that 


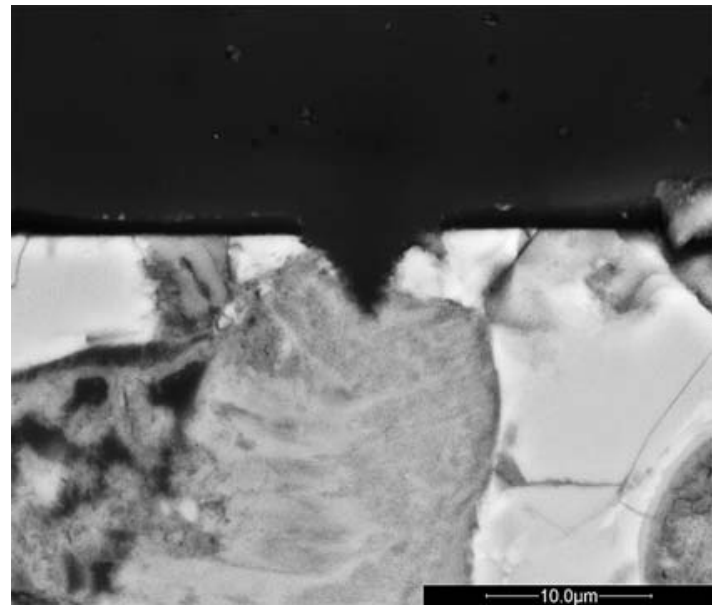

Fig. 13 ESEM image showing a cross-section of an ablation site of a multiple overlapping laser pulses of $3 \mu \mathrm{J}$ energy

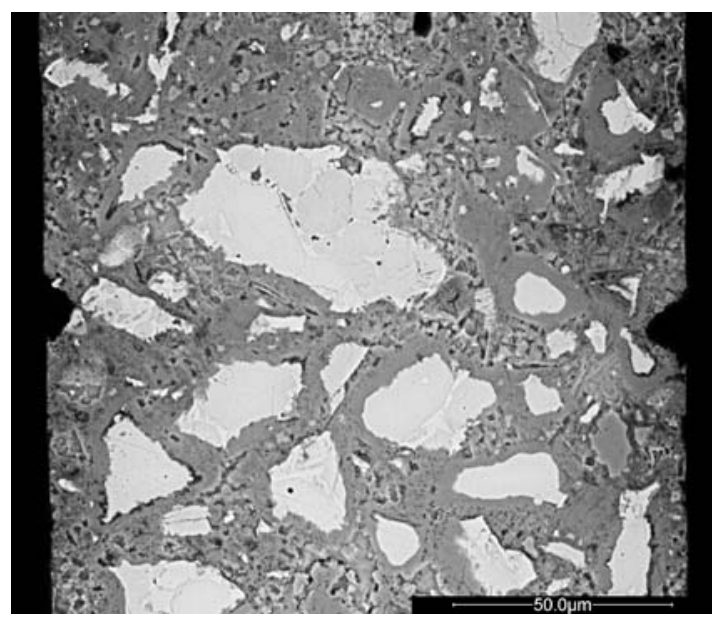

Fig. 14 ESEM image showing a cross-section of a cylindrical microspecimen of hardened Portland cement paste. Note the ablation sites on the sides of the specimen

could be clearly connected with laser ablation process had taken place. In some cases, a rim of increased porosity $(2-3 \mu \mathrm{m}$ in size) in the closest vicinity of the ablation site was observed (see Fig. 16).

\subsection{Synchrotron-based X-ray computed microtomography $\mathrm{SR} \mu \mathrm{CT}$}

In addition to electron microscopy, three of the microspecimens were also investigated using

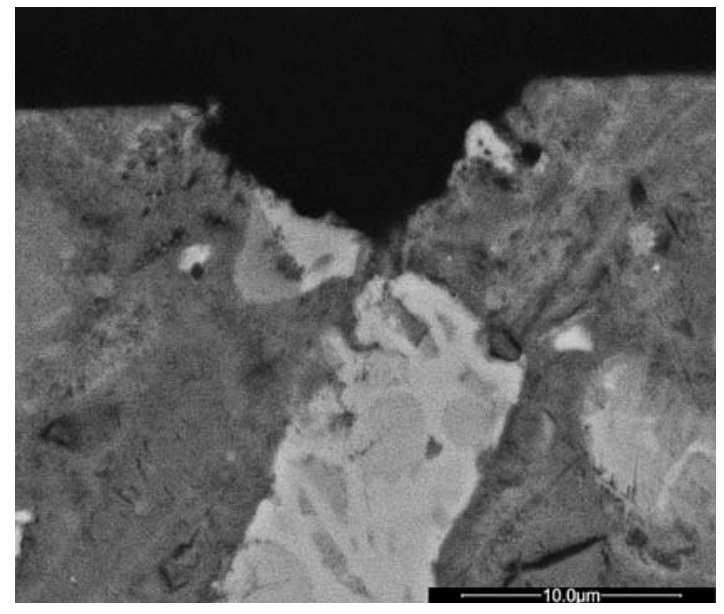

Fig. 15 Detail of the ablation site shown in Fig. 14

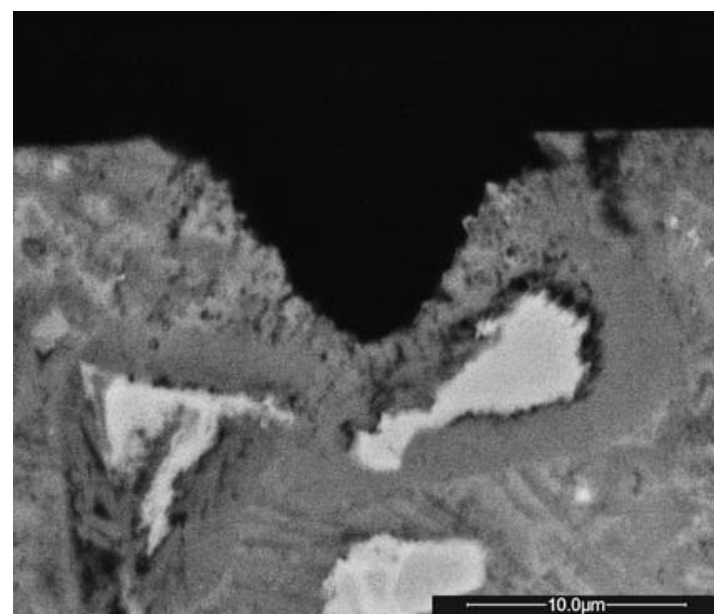

Fig. 16 Detail of the ablation site shown in Fig. 14

synchrotron-based X-ray computed microtomography $(\mathrm{SR} \mu \mathrm{CT}) . \mathrm{SR} \mu \mathrm{CT}$ is powerful technique for the three-dimensional assessment of microstructure of opaque materials with sub-micrometer resolution. The investigation has been carried out at the materials science beamline (MS-Tomo), Swiss Light Source, Paul Scherrer Institute, using a beam energy of $13.5 \mathrm{keV}$ and beam current of $300 \mathrm{~mA}$. Further details of the operating principles of this microtomography beamline are published elsewhere [9]. The voxel size of the microtomography output equalled $0.35 \mu \mathrm{m}$. The other parameters of the microtomography experiment are as follows: 
(i) the distance between the sample and scintillator was equal to $5.5 \mathrm{~mm}$,

(ii) YAG-scintillator of $20 \mu \mathrm{m}$ thickness has been utilised,

(iii) the number of projections used per tomogram equalled 451 with the exposure time of $2.5 \mathrm{~s}$ per projection.

From $\mathrm{SR} \mu \mathrm{CT}$, a three-dimensional model revealing the sub-surface microstructure of the ablation site was obtained. An example of a 3D reconstruction of $\mathrm{SR} \mu \mathrm{CT}$ data is shown in Fig. 17.

The depth of the notches was dependent on the experimental parameters and varied from 2 to 5 and 7 to $10 \mu \mathrm{m}$ for the sample micromachined with 24 and 96 laser pulses, respectively. The reconstruction showed that the size of the notch along the perimeter of the microcylinders was relatively uniform. The effect of the disordered structure of hardened cement pastes, containing stiffer and softer phases appeared to be limited. The exceptions are the domains of relatively large unhydrated particles positioned just below an ablation site. In that case, the unhydrated particle was - after micromachining - partially protruding from the adjacent material, hence decreasing locally the depth of the notch.

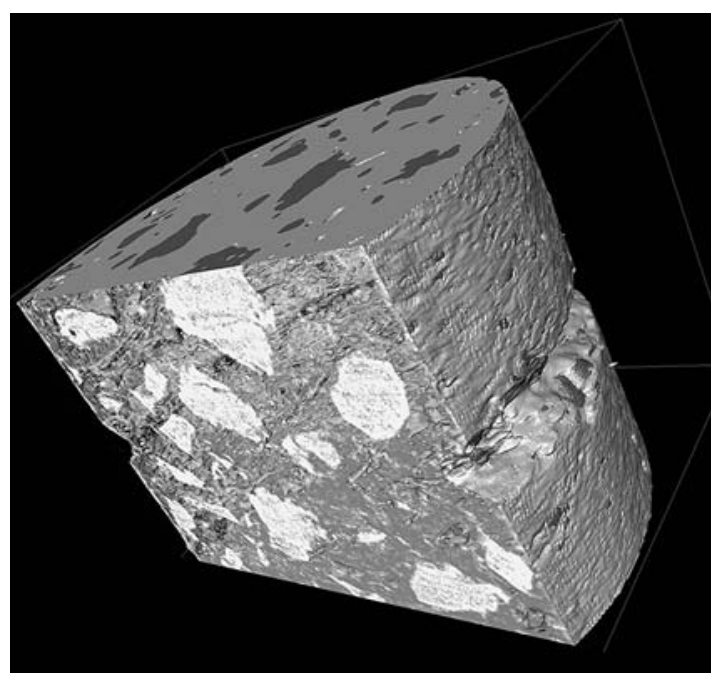

Fig. $17 \mathrm{SR} \mu \mathrm{CT}$ 3D reconstruction of a microcylinder clearly showing the notch produced by femtosecond laser pulses. It is possible to distinguish the unhydrated cement particles (white on cross section/dark grey on other surfaces), hydration products (grey) and porosity (translucent)

\section{Discussion}

Since hardened Portland cement is a multi-phase material, it is not surprising that various microstructural phases exhibit various ablation thresholds. The clear example of such different thresholds is shown in Fig. 18. Hardly any observable ablation occurred in the area of a large unhydrated cement particle.

Not all the unhydrated particles exhibited such resistance to ablation as the example shown in Fig. 18 (please compare with Fig. 6). Nevertheless, it is possible to conclude that, in general, unhydrated particles exhibited smaller/shallower ablation sites than the hydration products.

Based on the fact that hardened Portland cement paste is a moisture-sensitive material, femtosecond laser pulses provide a clear advantage over focused ion beam technique, because the laser system do not require to be operated in vacuum. Moreover, femtosecond laser pulses can be carried out on targets that are positioned in a water bath [10], and therefore there seems to be a scope for micromachining saturated moisturesensitive materials.

Another advantage of the femtosecond laser technique is that the machining is a relatively fast process. For example, the production time needed for the notch in the cylindrical microsample (disregarding both the time needed for the initial sample positioning and the time for the initial

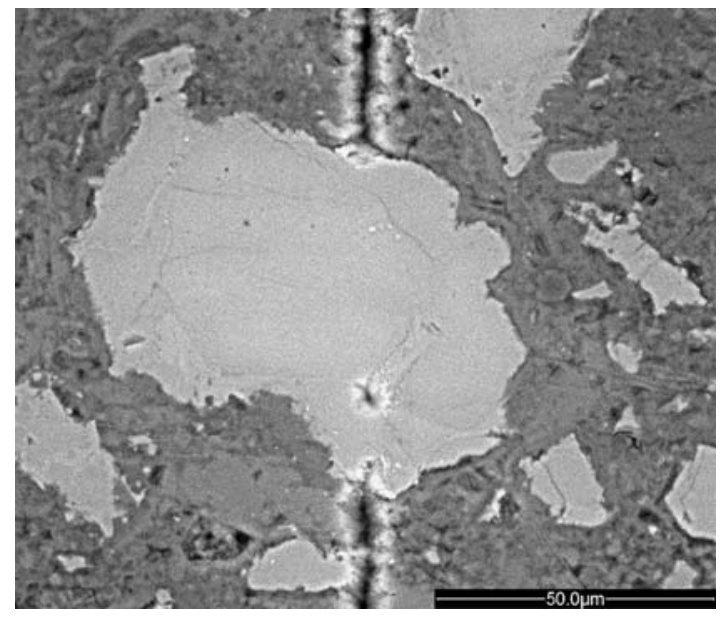

Fig. 18 BSE image of a groove of multiple overlapping laser pulses of $30 \mathrm{fs}$ length and $3 \mu \mathrm{J}$ energy showing hardly any ablation in unhydrated cement grain 
arrangement of the laser facility) has been in order of tens of seconds. Removal of the corresponding volume of material using focused ion beam technique is likely to require much longer time even when a high ion currents are used. Likely though, FIB may yield more accurate geometries.

\section{Conclusions}

It seems reasonable to suggest that femtosecond laser pulses can be successfully utilised for precision machining of microspecimens of hardened Portland cement pastes, given limitations set by its heterogeneity. The fs-laser pulses do not seem to induce excessive damage (i.e. microcracks) into the surface and sub-surface regions of the ablation sites.

From the 'real application' point of view, it was shown that the fabrication of a notch in a cylindrical microspecimen of hardened Portland cement paste is possible. Even though further detailed investigations of this topic are required, the authors suggest that the results presented above may open an avenue for fabrication of "damage-free" microspecimens of hardened Portland cement and other 3D disorder materials.

Acknowledgements The authors would like to thank all the members of the Institute for Building Materials, who helped with this project, in particular to Messrs Patrick Stähli, Martin Suter, Jürg Inhelder, Heinz Richner, Thomas Jaggi and Mrs Gabriele Peschke. Also, the authors would like to express many thanks to Prof. Jan G. M. van Mier for the comments to the paper. The contributions of Prof. Ursula Keller and Dr. Jens Biegert are gratefully acknowledged. Sincere thanks go to Prof. Eric Landis, Mrs Beatrix Hottiger and Miss Miluše Kousalová for proofreading the manuscripts. Thank to Holcim AG, Switzerland for the provision of a free batch of cement including the chemical analyses data. Part of this work was performed at the Swiss Light Source, Paul Scherrer Institute, Villigen, Switzerland. In particular, the contribution of Dr. Marco Stampanoni and Dr. Amela Grošo towards the microtomography experiments is also gratefully acknowledged.

\section{References}

1. Trtik P, Reeves CM, Bartos PJM (2000) Use of focused ion beam (FIB) for advanced interpretation of microindentation test results applied to cementitious composites. Mater Struc 33:189-193

2. Meijer J (2004) Laser beam machining (LBM), state of the art and new opportunities. J Mater Process Technol 149:2-17

3. Gorelik T, Will M, Nolte S, Tuennermann A, Glatzel U (2004) Transmission electron microscopy of femtosecond laser induced modifications in quartz. Appl Phy A - Mater Sci Process 76:309-311

4. Malshe A, Deshpande D (2004) Nano and microscale surface and sub-surface modifications induced in optical materials by femtosecond laser machining. J Mater Process Technol 149:585-590

5. Valette S, Audouard E, Le Harzic R, Huot N, Laporte P, Fortunier R, (2005) Heat affected zone in aluminum single crystals submitted to femtosecond laser irradiations. Appl Surface Sci 239:381-386

6. Rudolph P, Kautek W (2004) Composition influence of non-oxidic ceramics on self-assembled nanostructures due to fs-laser irradiation. Thin Sol Films 453-454:537-541

7. Rudolph P, Brzezinka KW, Wasche R, Kautek W (2003) Physical chemistry of the femtosecond and nanosecond laser-material interaction with $\mathrm{SiC}$ and a SiC-TiC-TiB2 composite ceramic compound. Appl Surface Sci 208:285-291

8. Borowiec A, Couillard M, Botton GA, Haugen HK (2004) Sub-surface damage in indium phosphide caused by micromachining of grooves with femtosecond and nanosecond laser pulses. Appl Phy A - Mater Sci Process 79:1887-1890

9. Stampanoni M, Borchert G, Wyss P, Abela R, Patterson B, Hunt S, Vermeulen D, Ruegsegger P (2002) High resolution X-ray detector for synchrotron-based microtomography. Nucl Instrum Meth Phys Res Sect A 491:291-301

10. Sylvestre JP, Kabashin AV, Sacher E, Meunier M (2005) Femtosecond laser ablation of gold in water: influence of the laser-produced plasma on the nanoparticle size distribution. Appl Phy A-Mater Sci Process 80:753-758 